\title{
Effects Of Patent Pools On Innovation Investment - Ex Ante Perspectives
}

\author{
Young-Kwan Kwon, Seoul National University, Korea \\ Yeonbae Kim, Seoul National University, Korea \\ Tai-Yoo Kim, Seoul National University, Korea \\ Yongil Song, Korea Institute of Science and Technology, Korea
}

\begin{abstract}
Recently Patent Pooling has a fast growing interest as a good alternative means to decrease transaction costs between IPRs owners and promote technology commercialization and diffusion. In this paper we attempt to shed light on the effects of patent pooling on the ex-ante innovation investment or incentive using the game theoretical economic model. We generalize the model by including many vertical integrated firms, research laboratories, and specialized manufacturing firms. Main results of this paper are: 1) Patent Pools can affect on the innovation incentives of vertically integrated firms(I-firms) and of research laboratories( $R$-firms) differently, and the effect depends on the number of I-firms owning essential patents and the number of specially manufacturing firms(M-firms). But in the presence of many I-firms owning essential patents, the instruction of patent pooling increases I-firms' ex-ante innovation incentive or investments with independence of $M$-firms. 2) There is strategic complementary relationship between innovation investments of I-firms and those of R-firms, so I-firms' increased ex-ante innovation investments make R-firms' ex-ante innovation investments increasing. 3) In the case of $R$-firms maximizing private profit, the best aspect is to license independently their patent technology when I-firms make up patent pools. But this aspect is not desirable for I-firms because I-firms' gross profit is smaller than that of I-firms which license their patent technologies independently. However, we show that in the cases of many I-firms owning essential patent technologies, patent pools including only I-firms $(I P)$ or all upstream firms $(C P)$ can affect asymmetrically on the I-firms' or $R$-firms' innovation investments. Nonetheless, any types of patent pools make the innovation investments of I-firms and R-firms higher than those of all firms which license independently. In summary, nowadays under general aspects that production of final goods requires many complex technologies and that many I-firms and R-firms attend $R \& D$ for essential technologies, competition authorities' deregulation for patent pooling or government policy supporting the patent pooling can promote upstream firms' innovation incentives or investments and compulsory licensing about $R$-firms is not necessary for enhancing upstream firms' innovation investments or incentives..
\end{abstract}

Keywords: innovation incentives, innovation investments, patent pools, licensing, strategic complementary

\section{INTRODUCTION}

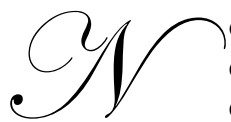
owadays, the interests on patent pools has a fast growing interest as a good alternative means to decrease transaction costs between IPRs owners and promote technology commercialization and diffusion. Patent pools have a very long history and Sewing machine pool at 1856 is known as the first patent pool(Gilbert, 2004). Recently U.S DoJ(Department of Justice) considers that the patent pools can have pro-competitive effects. In fact, U.S DoJ had affirmed MPEG, 3G, and DVD patent pools as pro-competitive.

Most Existent researches about patent pools mainly have been accomplished by lawyers or law school professors, but recently some economists published research papers on the patent pools. Shapiro(2001) analyzes the effects of paten pools on the downstream market using single-period static model and insists that patent pools can 
remove the complement problem under some strong assumptions. Kim(2004) expands the research of Shapiro(2001) by more realistic assumptions, that is, he includes the vertically-integrated firms in analyzing the effects of patent pools and assumes that downstream market is Cournot competition. The main results of Kim(2004) are that patent pools including the vertically integrated firms can remove complement problem and decrease double marginalization problem and rival's cost raising effects. On the other hand, Lerner \& Tirole(2004) developed a more tractable model with more alleviated assumptions such as imperfect complementarity of patents. They provide a necessary and sufficient condition for welfare-enhancing patent pools, and show that requiring patent pool members to have independent licensing is a screening mechanism for welfare-decreasing patent pools. Using the framework of Lerner \& Tirole(2004), Brenner(2005) provides a optimal pool formation mechanism which prevents welfaredecreasing pooling equilibrium from emerging but encourages welfare-enhancing pool formation. Brenner(2004) also shows that mandatory individual licensing is not an efficient screening mechanism for welfare-decreasing pools.

Choi(2003) analyzes the incentives to form patent pools or to engage in cross-licensing arrangements in the presence of uncertainty as to the validity and the coverage of patents. Aoki and Nagaoka(2005) show that a complete patent pool can be implemented only if the number of patent holders is small, and that emergence of an outsider is inevitable for large number of patent holders. Moreover, they also show that specialized research firms are more likely to become an outsider. Kato(2004) investigates a patent pool of substitute patents and show that a pool of substitute patents may promote the competition of downstream market under certain conditions and thereby enhance social welfare. Lerner et al.(2005) show empirically that the patent pools consisted of complementary patents are more likely to permit independent licensing of member.

However, existent literatures do not provide more detail analyses about effects of patent pools on innovators' innovation investment. Dequiedt \& Versaevel(2004) focus on this issues and analyze the impacts of possible pool formation on the ex-ante incentives to innovate. They show that a firm's investment pattern is upward sloping over time before pool formation but decrease dramatically after pool formation. Therefore, they insist that recently a general pool formation mechanism based on a proposal by the industry and acceptance/refusal by the competition authority may induce overinvestment in early innovations and lead to a delayed clearance date. However, Dequiedt \& Versaevel(2004) do not provide the asymmetric effects of possible patent pools on ex-ante innovation investments or incentives of different kind upstream firms and do not consider the strategic behavior of upstream firms. Therefore, in this paper we analyze this issues more detail based on strategic perspectives using a game theoretical economic model.

This paper is organized as follows. In the next section, we present our theoretical model. In the section 3, we derive market equilibriums for different kind of upstream firms. Then we show more details about the effects of patent pooling on ex-ante innovation investments or incentives of upstream firms. Finally this paper concludes with final remarks.

\section{MODEL}

In this paper, we use a generalized 3-stage game theoretical model and analyze the effects of patent pooling on the ex-ante innovation investments or incentives of upstream firms. Before detail analyses, we summarize main assumptions about technology and firms. We assume that each technology owned by all upstream firms is complementary and essential to produce final goods. That is, each downstream firm has to use one unit of each technology owned by all upstream firms to produce final goods. We also assume that there are no vertical restrictions in the package licensing through patent pools and per-unit royalty rates of all upstream firms is nondiscriminatory.

On the other hand, there are three kinds of firms for generalization of analysis. That is, we assume that there are $k$ vertically integrated firms attending both upstream and downstream market, and research laboratories attending only upstream market for example universities or government-funded research institutes. But we assume that there is only one research laboratory for the convenience without loss of generality. Finally, we assume that there are $n$ specialized manufacturing firms attending only final goods production and that the uncertainty at 
upstream and downstream market does not exist in. We also assume that all kinds of firms and consumers have complete information and final goods are homogeneous

Firms engage in R\&D, technology trade, and production. There are $k+1$ element technologies, each of which is essential in the production of the final goods. Of the $k+1$ firms, $k$ firms engage in both $\mathrm{R} \& \mathrm{D}$ and production, so these are called vertically integrated firms, which will be called as I-firms. The remaining one firm engages in only $R \& D$ and technology transfer and we will call it the R-firm. For example, we can regard research labs, universities, or government-funded research institutes as the example of R-firm. We also assume that there are $n$ specialized manufacturing firms, which will be called as M-firms, attending downstream market for producing final goods.

The order of play is as follows. In the first stage, all upstream firms(I-firms and R-firm) compete to develop each element technology and the innovation investments of each upstream firms are represented by $x_{i}(i=1, \cdots, k, R)$. In this stage, each upstream firm chooses R\&D investment level to maximize its expected value function. In the second stage, each upstream firm decides to license independently its own technology at a perunit royalty rate or collectively through patent pools at a pool royalty rate. Finally, in the third stage, I-firms produce final goods at zero cost save for license costs and engage in quantity competition(i.e. Cournot competition) in the product market independently and simultaneously. The products are assumed to be homogeneous and the inverse demand function is given by $P=a-b Q$, where $Q$ denotes the total industry output.

While each firm's profit functions are as follows. I-firms' gross profits are given by

$\pi_{i}=\left\{P-c_{i}\right\} q_{i}+l_{i} Q_{-i} \quad(i=1, \cdots, k)$

And R-firm's gross profit is given by

$\pi_{R}=l_{R} \times Q$

And M-firms' gross profits is given by

$$
\pi_{L j}=\left\{P-c_{j}\right\} \times q_{d j} \quad(j=1, \cdots, n)
$$

where $c_{i}$ and $c_{j}$ mean the marginal costs of vertically integrated firms and specialized manufacturing firms respectively. For the convenience of analysis, we will simplify our model by assuming that all downstream firms, Ifirms and M-firms, produce final goods using the same production technologies and the each firm's marginal cost is the per-unit royalties for licensing in element technologies, that is, marginal production costs for all downstream firms are zero. We also assume that marginal costs $c_{i}$ and $c_{j}$ are low enough. Under these assumptions, marginal $\operatorname{cost} c_{i}$ of I-firm $i$ is equal to $l_{R}+\sum_{j \neq i}^{k} l_{i}$ and marginal cost $c_{j}$ of M-firms is $l_{R}+\sum_{i=1}^{k} l_{i}$, where $l_{R}$ means the perunit royalty rate of R-firm and $l_{i}$ the per-unit royalty rate of I-firm $i(i=1, \cdots, k)$.

\section{PRODUCTION AND LICENSING}

The game can be solved by backward induction. The equilibrium gross profits, royalty rates, production quantities of final goods, industry output, and price of final goods are dependent on whether upstream firms license independently their technologies or collectively through patent pools at technology transfer stage $\left(2^{\text {nd }}\right.$ stage). Because R-firm that creates profits from royalty revenues can have incentive for independent licensing even in the case of patent pooling including all I-firms, we obtain the equilibrium gross profits for three cases and then analyze the innovation investment of upstream firms at innovation stage (i.e., $1^{\text {st }}$ stage). 


\subsection{Independent Licensing}

First of all, let us analyze the final goods production stage $\left(3^{\text {rd }}\right.$ stage $)$. In the independent licensing case, only I-firms produce final goods because there is asymmetry in the cost structure between I-firms and M-firms. That is, M-firms can attend in the final goods production market by paying royalties to all upstream firms, but I-firms don't have to pay royalty for their own patent technology. I-firm $i(i=1, \cdots, k)$ sets quantity $q_{i}$ to maximize its expected gross profit $\pi_{i}$ given by (2.1). Solving for the first-order conditions;

$$
\frac{\partial \pi_{i}}{\partial q_{i}}=\left\{a-b Q-\left(l_{R}+\sum_{j \neq i}^{k} l_{j}\right)\right\}-b q_{i}=0 \quad(i=1, \cdots, k)
$$

From above FOCs for profit maximization, we can obtain the equilibrium industry gross output as follow.

$$
Q^{I N}=\frac{k\left(a-l_{R}\right)-(k-1) L}{(k+1) b}
$$

where $L \equiv \sum_{j=1}^{k} l_{j}$. And the equilibrium final goods production quantity of I-firm $i(i=1, \cdots, k)$ is given by

$$
q_{i}^{I N}=\frac{\left(a-l_{R}\right)-2 L_{-i}+(k-1) l_{i}}{(k+1) b} \quad(i=1, \cdots, k)
$$

where $L_{-i} \equiv \sum_{j \neq i}^{k} l_{j}$. Therefore, we can obtain I-firm $i$ 's $(i=1, \cdots, k)$ and R-firm's equilibrium profits from equation (2.1) and (2.2) as follow

$$
\begin{aligned}
& \pi_{i}^{I N}=\left\{a-b Q^{I N}-\left(l_{R}+L_{-i}\right)\right\} q_{i}^{I N}+l_{i} Q_{-i}^{I N} \\
& \pi_{R}^{I N}=l_{R} \times Q^{I N}=l_{R} \times\left[\frac{k\left(a-l_{R}\right)-(k-1) L}{(k+1) b}\right]
\end{aligned}
$$

Now let us go back one step to the technology transfer stage. In this stage, all upstream firms which have each essential technology maximize their own gross profits by imposing optimal royalty rates independently.

First, we analyze the case where each firm individually sets its own royalty rates $c_{i}$ freely to maximize its own expected gross profit. From $\pi_{i}^{I N}(i=1, \cdots, k)$ and $\pi_{R}^{I N}$, the first-order conditions for I-firm $i(i=1, \cdots, k)$ and for R-firms reduce to

$$
\begin{aligned}
& \frac{\partial \pi_{i}^{I N}}{\partial l_{i}}=\frac{\partial}{\partial l_{i}}\left[\left\{a-b Q^{I N}-\left(l_{R}+L_{-i}\right)\right\} q_{i}^{I N}+l_{i} Q_{-i}^{I N}\right]=0 \\
& \frac{\partial \pi_{R}^{I N}}{\partial l_{R}}=\frac{\partial}{\partial l_{R}}\left[l_{R} \times Q^{I N}\right]=0
\end{aligned}
$$


From equation (3.4) and (3.5), we can obtain the optimal equilibrium royalty rates for each firm as follow

$$
\begin{aligned}
& l_{i}^{I N}=\frac{k+3}{k^{2}+6 k+1} a \quad(i=1, \cdots, k) \\
& l_{R}^{I N}=\frac{2(k+1)}{k^{2}+6 k+1} a
\end{aligned}
$$

Therefore, substituting (3.6) and (3.7) in (3.2), (3.3), (2.1)', and (2.2)', the maximized equilibrium gross profit for I-firms and R-firm are given by

$$
\begin{aligned}
& \pi_{i}^{I N}=\left(\frac{a^{2}}{b}\right) \frac{2\left(k^{2}+2 k-1\right)}{\left(k^{2}+6 k+1\right)^{2}} \quad(i=1, \cdots, k) \\
& \pi_{R}^{I N}=\left(\frac{a^{2}}{b}\right) \frac{4 k(k+1)}{\left(k^{2}+6 k+1\right)^{2}}
\end{aligned}
$$

\subsection{Patent Pooling Among I-firms(IP)}

Second, let us analyze the case that all I-firms agree with attending a patent pool but R-firm dose not attend the patent pool. In the convenience, let us call this type of patent pool as Incomplete patent pool(IP). Of course, we can consider other cases that some I-firms attend a patent pool, but we will not consider these cases. We also assume that the patent pool set collectively a per-unit royalty rate $l_{I P}$ and that each member I-firm shares the royalty rate and the royalty share of I-firm $i(i=1, \cdots, k)$ is $\theta_{i}\left(\sum_{i=1}^{k} \theta_{i}=1\right)$. Therefore, gross profit functions of I-firm $i(i=1, \cdots, k)$, R-firm, and M-firms $j(j=1, \cdots, n)$ are given by

$$
\begin{array}{ll}
\pi_{i}=\left\{P-\left(l_{R}+l_{I P}\right)\right\} q_{i}+\theta_{i} l_{I P} Q & (i=1, \cdots, k) \\
\pi_{R}=l_{R} \times Q & \\
\pi_{L j}=\left\{P-\left(l_{R}+l_{I P}\right)\right\} q_{d j} & (j=1, \cdots, n)
\end{array}
$$

I-firms and $\mathrm{M}$-firms produce final goods at production stage( $3^{\text {rd }}$ stage $)$. The FOCs for profit maximization of I-firm $i(i=1, \cdots, k)$ and M-firm $j(j=1, \cdots, n)$ are given by

$$
\begin{array}{ll}
\frac{\partial \pi_{i}}{\partial q_{i}}=\left\{a-b Q-\left(l_{R}+l_{I P}\right)\right\}-b q_{i}+\theta_{i} l_{I P}=0 & (i=1, \cdots, k) \\
\frac{\partial \pi_{L j}}{\partial q_{d j}}=\left\{a-b Q-\left(l_{R}+l_{I P}\right)\right\}-b q_{d j}=0 & (j=1, \cdots, n)
\end{array}
$$

From above FOCs for profit maximization, we can obtain the equilibrium industry gross output, quantity of I-firm $i(i=1, \cdots, k)$ and M-firm $j(j=1, \cdots, n)$ as follow. 


$$
\begin{array}{ll}
Q^{I P}\left(l_{R}, l_{I P}\right)=\frac{(k+n) a-(k+n) l_{R}-(k+n-1) l_{I P}}{(k+n+1) b} & \\
q_{i}^{I P}\left(l_{R}, l_{I P}\right)=\frac{\left(a-l_{R}\right)+\left\{(k+n+1) \theta_{i}-2\right\} l_{I P}}{(k+n+1) b} & (i=1, \cdots, k) \\
q_{d j}^{I P}\left(l_{R}, l_{I P}\right)=\frac{\left(a-l_{R}\right)-2 l_{I P}}{(k+n+1) b} & (j=1, \cdots, n)
\end{array}
$$

Therefore, we can obtain I-firm $i$ 's, R-firm's, and M-firm $j$ 's equilibrium profits from equation (3.10), (3.11), and (3.12) as follow

$$
\begin{aligned}
& \pi_{i}^{I P}=\left[\frac{a-l_{R}-2 l_{I P}}{(k+n+1)}\right] \times\left[\frac{a-l_{R}+\left\{(k+n+1) \theta_{i}-2\right\} l_{I P}}{(k+n+1) b}\right] \\
& +\theta_{i} l_{I P}\left[\frac{(k+n)\left(a-l_{R}\right)-(k+n-1) l_{I P}}{(k+n+1) b}\right] \quad(i=1, \cdots, k) \\
& \pi_{R}^{I P}=l_{R} \times Q^{I P}=l_{R} \times\left[\frac{(k+n)\left(a-l_{R}\right)-(k+n-1) l_{I P}}{(k+n+1) b}\right] \\
& \pi_{L j}^{I P}=\frac{\left[a-l_{R}-2 l_{I P}\right]^{2}}{(k+n+1)^{2} b} \\
& (j=1, \cdots, n)
\end{aligned}
$$

In the technology transfer stage $\left(2^{\text {nd }}\right.$ stage $), \mathrm{R}$-firm independently maximize its own gross $\operatorname{profits}\left(\pi_{R}^{I P}\right)$ but all I-firms maximize the pooled profit that means the summation of all I-firms' gross profits $\left(\sum_{i=1}^{k} \pi_{i}^{I P}\right)$. From this optimization, the optimal equilibrium royalty rates are given by

$l_{I P}=\frac{k+n}{3(k+n)+1} a, \quad l_{R}=\frac{k+n+1}{3(k+n)+1} a$

Therefore, substituting (3.17) in (3.10)', (3.11)' and (3.12)', the maximized equilibrium gross profits for Ifirms and R-firm are given by

$$
\begin{array}{ll}
\pi_{i}^{I P}=\theta_{i}\left(\frac{a^{2}}{b}\right)\left[\frac{(k+n)^{2}}{3(k+n)+1}\right] & (i=1, \cdots, k) \\
\pi_{R}^{I P}=\left(\frac{a^{2}}{b}\right)\left[\frac{(k+n)(k+n+1)}{3(k+n)+1}\right] & \\
\pi_{L j}^{I P}=0 & (j=1, \cdots, n)
\end{array}
$$




\subsection{Patent Pooling Among All Upstream Firms(CP)}

Finally, let us analyze the case that all I-firms and R-firms agree with attending a patent pool. We call this type patent pool as complete patent pool(CP). In this case, all upstream firms(I-firms and R-firm) set a per-unit royalty rate of the pool, $l_{C P}$, and each firm share the royalty rate. We assume that the royalty shares of R-firm and Ifirm $i$ individually is $\theta_{R}$ and $\theta_{i}$. Then sum of all upstream firms' share has to be equal to 1, i.e. $\theta_{R}+\sum_{i=1}^{k} \theta_{i}=1$. Therefore, Gross profits of I-firm $i(i=1, \cdots, k)$, R-firm, and M-firms $j(j=1, \cdots, n)$ is given by

$$
\begin{array}{ll}
\pi_{i}=\left\{P-l_{C P}\right\} q_{i}+\theta_{i} l_{C P} Q & (i=1, \cdots, k) \\
\pi_{R}=\theta_{R} l_{C P} \times Q & \\
\pi_{L j}=\left\{P-l_{C P}\right\} q_{d j} & (j=1, \cdots, n)
\end{array}
$$

We can obtain the optimal royalty rate of the pool and the equilibrium gross profits for I-firms, R-firm, and M-firms by the same process with the previous section. We summarize the results as follow

$$
\begin{aligned}
l_{C P}= & \left(\frac{a}{2}\right) \cdot\left[\frac{(k+n+1)(k+n)+(n+1)\left(\sum \theta_{i}\right)-2 k-k\left(\sum \theta_{i}\right)}{(k+n+1)(k+n)+(n+1)\left(\sum \theta_{i}\right)^{2}-2 k\left(\sum \theta_{i}\right)-k}\right] \\
\pi_{i}^{C P}= & {\left[\frac{a-\left(1+\sum \theta_{i}\right) l_{C P}}{(k+n+1)}\right] \times\left[\frac{a+\left\{(k+n+1) \theta_{i}-\left(1+\sum \theta_{i}\right)\right\} l_{C P}}{(k+n+1) b}\right] } \\
& +\theta_{i} l_{C P}\left[\frac{(k+n) a-\left(k+n-\sum \theta_{i}\right) l_{C P}}{(k+n+1) b}\right] \quad(i=1, \cdots, k) \\
\pi_{R}^{I P}= & \theta_{R} l_{C P}\left[\frac{(k+n) a-\left(k+n-\sum \theta_{i}\right) l_{C P}}{(k+n+1) b}\right] \quad(j=1, \cdots, n) \\
\pi_{L j}^{C P}= & \frac{\left[a-\left(1+\sum \theta_{i}\right) l_{C P}\right]^{2}}{(k+n+1)^{2} b}
\end{aligned}
$$

\subsection{Comparison Of Upstream Firms' Equilibrium Gross Profits}

To analyze the innovation investments of I-firms and R-firm attending innovation stage, we have to obtain the expected value function for upstream firms at that stage. Therefore, it is necessary to compare the gross profits of upstream firms that depend on the licensing mechanism at technology transfer stage $\left(2^{\text {nd }}\right.$ stage $)$. For the patent pool cases, we assume that royalty share among upstream firms attending the patent pool is allocated based on the prorata rule. In reality, many patent pools introduce this rule for royalty allocation. Under this assumption, we can summarize the gross profits of I-firms and R-firm according to independent licensing, incomplete patent pool, and complete patent pool as follow. Here we do not give the proof of following propositions because we can easily understand the results by simple comparison. 


\section{Proposition 1.}

Given that all the component technologies have been successfully developed, the equilibrium gross profits of I-firms according to the licensing strategies satisfy the following:

$$
\begin{aligned}
& \text { In the case of small number of licensors, I-firms }(2 \leq k \leq 7), \pi_{i}^{C P}>\pi_{i}^{I N}>\pi_{i}^{I P} \\
& \text { In the case of large number of licensors, I-firms }(k \geq 8), \pi_{i}^{C P}>\pi_{i}^{I P}>\pi_{i}^{I N}
\end{aligned}
$$

For vertically-integrated I-firms, we can see that the complete patent pooling in the technology transfer stage is the most desirable licensing mechanism with independence of I-firms' number. Moreover, we also can see that the results of proposition 1 do not change according to the number of M-firms.

\section{Proposition 2.}

Given that all the component technologies have been successfully developed, the equilibrium gross profits of R-firms according to the licensing strategies satisfy the following:

(1) In the case of $k=2, \pi_{R}^{I P}>\pi_{R}^{I N}>\pi_{R}^{C P}$ for the enough large $n$

In the case of $k=3, \pi_{R}^{I P}>\pi_{R}^{I N}>\pi_{R}^{C P}$ for $0 \leq n \leq 7$, and $\pi_{R}^{I P}>\pi_{R}^{C P}>\pi_{R}^{I N}$ for $n \geq 8$

In the case of $k=4, \pi_{R}^{I P}>\pi_{R}^{I N}>\pi_{R}^{C P}$ for $n=0$, and $\pi_{R}^{I P}>\pi_{R}^{C P}>\pi_{R}^{I N}$ for $n \geq 1$

In the case of $k=5, \pi_{R}^{I P}>\pi_{R}^{C P}>\pi_{R}^{I N}$ for any number of M-firms $(\forall n \geq 0)$

For research laboratory R-firm, we can see that the incomplete patent pool with all I-firms but R-firm is the most desirable aspect with independence of the number of I-firms and M-firms.

\section{INNOVATION INVESTMENT}

Now let us analyze the innovation staege $\left(1^{\text {st }}\right.$ stage $)$. To analyze ex-ante innovation investments or incentives of upstream firms, we use well-developed patent race model(Reinganum 1983, 1986). In general, patent race models assume that firms compete for developing a same innovation. Therefore, patent race models may not be suitable to our model because we assume that all upstream firms invest their R\&D resources to a different but complementary element technology. But according to the empirical study on the Racing to invest in pharmaceutical R\&D by Cockburn and Henderson(1994), the patent race model is more suitable to a race related to the multiple prize and a continual complementarities between innovations developed by competing firms. Therefore, stochastic patent race model can be appropriate to analyze the ex-ante innovation investments for our multiple element technology development, so we can use the patent race model to analyze the effects of patent pools on the ex-ante innovation investments or incentives.

In the innovation investment stage, all upstream firms, I-firms and R-firm, want to maximize their expected value function. The discounted present value function of expected value for any upstream firm $i(i=1, \cdots, k, R)$ at the first stage, is given by

$$
\begin{aligned}
V^{i}\left(x_{1}, \cdots, x_{k}, x_{R}\right) & =\int_{0}^{\infty} e^{-r t}\left(e^{-\left[h\left(x_{1}\right)+\cdots h\left(x_{k}\right)+h\left(x_{R}\right)\right] t} \times\left[-x_{i}+h\left(x_{1}\right) \cdots h\left(x_{k}\right) h\left(x_{R}\right) \frac{\pi_{i}}{r}\right]\right) d t \\
= & \frac{-x_{i}+h\left(x_{1}\right) \cdots h\left(x_{k}\right) h\left(x_{R}\right) \frac{\pi_{i}}{r}}{r+h\left(x_{1}\right)+\cdots h\left(x_{k}\right)+h\left(x_{R}\right)} \quad(i=1, \cdots, k, R)
\end{aligned}
$$


An upstream firm $i$ 's R\&D success probability by time $t$ is represented by $F(t)=1-e^{-h\left(x_{i}\right) t}$, where $h\left(x_{i}\right)$ is hazard rate function and satisfies $h\left(x_{i}\right)=\frac{f(t)}{1-F(t)}$ and $f(t)=\frac{d F(t)}{d t}$.

The objective of all upstream firms is choosing the innovation investment level $x_{i}$ maximizing their expected value function (4.1). Before detailed analysis, we assume that hazard rate function $h(x)$ satisfies $h^{\prime}(\bullet)>0, h^{\prime \prime}(\bullet)<0$. Maximization problem of I-firm $i$ 's expected value function is given by $\max _{x_{i}} V^{i}\left(x_{1}, \cdots, x_{k}, x_{R}\right)$ and the FOC is given by solving $V_{i}^{i} \equiv \frac{\delta V^{i}}{\delta x_{i}}=0$. Thus we can obtain the FOC as follow (See Appendix)

$$
\begin{array}{r}
\left(-1+h^{\prime}\left(x_{1}\right) \cdots h^{\prime}\left(x_{k}\right) h^{\prime}\left(x_{R}\right) \frac{\pi_{i}}{r}\right)\left[r+h\left(x_{1}\right)+\cdots+h\left(x_{k}\right)+h\left(x_{R}\right)\right] \\
-\left(-x_{i}+h\left(x_{1}\right) \cdots h\left(x_{k}\right) h\left(x_{R}\right) \frac{\pi_{1}}{r}\right) \cdot h^{\prime}\left(x_{i}\right)=0
\end{array}
$$

While we can confirm that the $\operatorname{SOC}\left(V_{i i}^{i} \equiv \frac{\delta^{2} V^{i}}{\delta x_{i}^{2}}=\frac{\delta V_{i}^{i}}{\delta x_{i}}<0\right)$ for the maximization problem is satisfied (See Appendix). Moreover, we can obtain the sign of $V_{i j}^{i} \equiv \frac{\delta^{2} V^{i}}{\delta x_{i} \delta x_{j}}=\frac{\delta V_{i}^{i}}{\delta x_{j}} \quad(j=1, \cdots i-1, i+1, \ldots k, R)$ is positive from FOC (4.2) (See Appendix). Thus we can easily understand that the above results can be generalized as follow

$$
V_{i i}^{i}<0, V_{i j}^{i}>0 \quad(i=1, \cdots, k, R ; j=1, \cdots, i-1, i+1, k, R)
$$

Therefore, we can suggest following proposition.

\section{Proposition 3.}

The innovation investment between I-firms and R-firm is strategic complement.

Proof) The total derivative of eq'n (4.2) about $x_{1}, \cdots, x_{k}, x_{R}, K_{i}\left(\equiv \frac{\pi_{i}}{r}\right)$ is given by

$d V_{i}^{i}=V_{i 1}^{i} d x_{1}+\cdots V_{i i}^{i} d x_{i}+\cdots+V_{i k}^{i} d x_{k}+V_{i R}^{i} d x_{R}+V_{i K_{i}}^{i} d K_{i}=0$

From implicit function theorem, the best response curve of I-firms about R-firm or R-firm about any Ifirms is positive slope. That is, $\left.\frac{d x_{I}\left(x_{R}\right)}{d x_{R}}\right|_{K_{I}=\frac{\pi_{I}}{r}}=-\frac{V_{I R}^{I}}{V_{I I}^{I}}>0$ and $\left.\frac{d x_{R}\left(x_{I}\right)}{d x_{I}}\right|_{K_{R}=\frac{\pi_{R}}{r}}=-\frac{V_{I R}^{R}}{V_{R R}^{R}}>0$ are satisfied from SOC and (4.3), where $I$ and $R$ indicate any I-firms and R-firm respectively. $\quad$ Q.E.D. 
Now let us investigate the Nash equilibrium of innovation investment for I-firms and R-firm. Here our main interest is the interaction of R\&D investment between I-firms and R-firm. From above proposition3, the innovation investments between I-firms and R-firm are strategic complement. This means that the increase in Ifirms' innovation investment gives rise to the increase in R-firm's innovation investment. Therefore, the Nash equilibrium is the intersection of I-firms' best response curve and I-firm's best response curve. Here let us assume that $\left|V_{I I}^{I}\right|>\left|V_{I R}^{I}\right|$ and $\left|V_{R R}^{R}\right|>\left|V_{I R}^{R}\right|$ are satisfied because of the stability of the equilibrium.

Finally, we can see the effects of patent pools on the ex-ante innovation investments of the upstream firms, I-firms and R-firms, by the shift of each firm's best response curve from the changes in their gross profits. For this purpose, we have to investigate the sign of $\left.\frac{d x_{I}}{d K_{I}}\right|_{x_{R}}$ and $\left.\frac{d x_{R}}{d K_{R}}\right|_{x_{I}}$ for any I-firms. From simple calculus, we can see that the sign of $V_{I K_{I}}^{I} \equiv \frac{\delta}{\delta K_{I}}\left(\frac{\delta V^{I}}{\delta x_{I}}\right)$ is positive for any I-firms, and the sign of $V_{R K_{R}}^{R} \equiv \frac{\delta}{\delta K_{R}}\left(\frac{\delta V^{R}}{\delta x_{R}}\right)$ is positive (See appendix). Therefore, $\left.\frac{d x_{I}}{d K_{I}}\right|_{x_{R}}$ and $\left.\frac{d x_{R}}{d K_{R}}\right|_{x_{I}}$ have positive sign by implicit function theorem from eq'n (4.4). Thus this means that the increase of any upstream firms' gross profits enhances their ex-ante innovation investments..

From the above propositions and the positive effects of gross profits on the ex-ante innovation investments, we can suggest following proposition.

\section{Proposition 4.}

The equilibrium ex-ante innovation investment of upstream firms according to different licensing strategies satisfies the following:

(1) In the case of $k=2, x_{R}^{I P}>x_{R}^{I N}>x_{R}^{C P}$ and $x_{I}^{C P}>x_{I}^{I N}>x_{I}^{I P}$ for the enough large $n$

(2) In the case of $\quad k=3, \quad x_{R}^{I P}>x_{R}^{I N}>x_{R}^{C P}$ and $x_{I}^{C P}>x_{I}^{I N}>x_{I}^{I P}$ for $0 \leq n \leq 7$, and $x_{R}^{I P}>x_{R}^{C P}>x_{R}^{I N}$ and $x_{I}^{C P}>x_{I}^{I N}>x_{I}^{I P}$ for $n \geq 8$

(3) In the case of $k=4, x_{R}^{I P}>x_{R}^{I N}>x_{R}^{C P}$ and $x_{I}^{C P}>x_{I}^{I N}>x_{I}^{I P}$ for $n=0$, and $x_{R}^{I P}>x_{R}^{C P}>x_{R}^{I N}$ and $x_{I}^{C P}>x_{I}^{I N}>x_{I}^{I P}$ for $n \geq 1$

(4) In the case of $5 \leq k \leq 7, x_{R}^{I P}>x_{R}^{C P}>x_{R}^{I N}$ and $x_{I}^{C P}>x_{I}^{I N}>x_{I}^{I P}$ for any number of M-firms $(\forall n \geq 0)$

(5) In the case of $k \geq 8, x_{R}^{I P}>x_{R}^{C P}>x_{R}^{I N}$ and $x_{I}^{C P}>x_{I}^{I P}>x_{I}^{I N}$ for any number of M-firms $(\forall n \geq 0)$

From proposition4, we can see that in the cases of many I-firms owning essential patent technologies, patent pools including only I-firms or all upstream firms can affect asymmetrically on the I-firms' or R-firms' innovation investments. Nonetheless, any types of patent pools make the innovation investments of I-firms and Rfirms higher than those of all firms licensing independently. Therefore, it is very important findings of our research that patent pooling promotes the ex-ante innovation investments of any kind of upstream firms and thus the technologies essential to produce final goods can be developed more fast under possible patent pooling. These results have very important implications to antitrust or competition policy. 


\section{CONCLUDING REMARKS}

Recently Patent Pools have a fast growing interest as a good alternative means to decrease transaction costs between IPRs owners and promote technology commercialization and diffusion. We attempt to shed light on the effects of possible patent pools on the upstream firms' innovation incentives or investments. Under ex-ante perspectives, we show that patent pools can asymmetrically affect on the innovation incentive of vertically integrated firms(I-firms) and of research laboratories(R-firms) differently, and the effects depend on the number of I-firms owning essential patents and the number of specially manufacturing firms(M-firms). But in the presence of many I-firms owning essential patents, instruction of patent pooling can increase I-firms' ex-ante innovation incentive or investments with independence of M-firms. We also show that there is strategic complementary relationship between innovation investments of I-firms and those of R-firms, so I-firms' increased ex-ante innovation investments make R-firms' ex-ante innovation investments increasing. Moreover, in the case of R-firms maximizing private profit, the best aspect is to license independently their patent technology when I-firms make up patent pools. But this aspect is not desirable for I-firms because I-firms' gross profit is smaller than that of I-firms which are licensing their patent technologies independently. However, we show that in the cases of many I-firms owning essential patent technologies, patent pools including only I-firms(IP) or all upstream firms(CP) can affect asymmetrically on the I-firms' or R-firms' innovation investments. Nonetheless, any types of patent pools make the innovation investments of I-firms and R-firms higher than those of all firms which are licensing independently. In summary, nowadays under general aspects that production of final goods requires many complex technologies and that many I-firms and R-firms attend R\&D for essential technologies, competition authorities' deregulation for patent pooling or government policy supporting the patent pooling can promote upstream firms' innovation incentives or investments and compulsory licensing about R-firms is not necessary for enhancing upstream firms' innovation investments or incentives. Our research is based on the ex-ante perspectives, so the empirical analysis about the effects of patent pooling still remains an important future work.

\section{REFERENCES}

1. Atsushi Kato, Patent pool enhances market competition, International Review of Law and Economics 24, 2004, pp.255-268.

2. Cockburn, I. and R. Henderson, Racing to Invest? The Dynamics of Competition in Ethical Drug Discovery, Journal of Economics and Management Strategy 3, 1994, pp.381-519..

3. J.P. Choi, Patnet Pools and Cross-licensing in the shadow of patent litigation, CESifo Working paper No.1070, 2003.

4. Lerner, Josh and Tirole, Jean, Efficient Patent Pools, American Economic Review 93(3), 2004, pp.691-711.

5. Lerner, Strojawas and Tirole, The Structure and Performance of Patent Pools: Empirical Evidence, Working paper, 2003.

6. Reiko Aoki and Sadao Nagaoka, Coalition formulation for a consortium standard through a standard body and a patent pool: Theory and evidence from MPEG2, DVD and 3G, Working paper, 2005.

7. Reiko Aoki and Sadao Nagaoka, The Consortium Standard and Patent, Working paper, 2004.

8. Reinganum, J., Uncertain Innovation and the Persistence of Monopoly, American Economic Review 73, 1983, pp.741-526.

9. Reinganum, J., Uncertainty, Industrial Structure, and the Speed of R\&D, Econometrica 50, 1982, pp.671688.

10. Richard J. Gilbert, Antitrust for patent pools: A century of policy evolution, Standford Technology Law Review(3), 2004.

11. Steffen Brenner, Optimal formulation rules for patent pools, Working paper, 2005.

12. Steffen Brenner, Stable patent pools, Working paper, 2004.

13. Sung-hwan Kim, Vetical structure and patent pools, Review of Industrial Organizations 25, 2004, pp.231250 .

14. V. Dequiedt and B. Versaevel, Patent Pools and the dynamic incentives to R\&D, Working paper, 2004. 


\section{APPENDIX}

Proof of FOCs (4.2)

From (4.1), let us differentiate the expected value of firm $i$ with respect to $x_{i}$.

$$
V_{i}^{i} \equiv \frac{\partial V^{i}}{\partial x_{i}}=\frac{1}{\mathrm{~A}^{2}} \cdot\left[\begin{array}{c}
\left(-1+h\left(x_{1}\right) \cdots h^{\prime}\left(x_{i}\right) \cdots h\left(x_{k}\right) h\left(x_{R}\right) \frac{\pi_{i}}{r}\right) \cdot \mathrm{A} \\
-\left(-x_{i}+h\left(x_{1}\right) \cdots h\left(x_{k}\right) h\left(x_{R}\right) \frac{\pi_{i}}{r}\right) \cdot h^{\prime}\left(x_{i}\right)
\end{array}\right]=0
$$

where A indicates $\left[r+h\left(x_{1}\right)+\cdots+h\left(x_{k}\right)+h\left(x_{R}\right)\right]$ and has positive sign under non-zero discounted rate, therefore FOC is given by (4.2). $\quad$ Q.E.D.

\section{Proof of satisfying SOC for the expected value maximization problem}

We can check whether SOC is satisfied by differentiation of FOC. That is, $V_{i i}^{i}$ is the differentiation of firm $i$ 's FOC with respect to $x_{i}$.

$$
\begin{aligned}
& V_{i i}^{i} \equiv \frac{\partial^{2} V^{i}}{\partial x_{i}^{2}}=\frac{\partial}{\partial x_{i}}\left(\frac{\partial V^{i}}{\partial x_{i}}\right)=\frac{\partial V_{i}^{i}}{\partial x_{i}} \\
& =\frac{\partial}{\partial x_{i}}\left[\begin{array}{c}
\frac{\left(-1+h\left(x_{1}\right) \cdots h^{\prime}\left(x_{i}\right) \cdots h\left(x_{k}\right) h\left(x_{R}\right) \frac{\pi_{i}}{r}\right)}{\mathrm{A}} \\
-\frac{\left(-x_{i}+h\left(x_{1}\right) \cdots h\left(x_{k}\right) h\left(x_{R}\right) \frac{\pi_{i}}{r}\right) \cdot h^{\prime}\left(x_{i}\right)}{\mathrm{A}^{2}}
\end{array}\right] \\
& =\frac{1}{\mathrm{~A}^{2}}\left[\begin{array}{r}
\left(h\left(x_{1}\right) \cdots h^{\prime \prime}\left(x_{i}\right) \cdots h\left(x_{k}\right) h\left(x_{R}\right) \frac{\pi_{i}}{r}\right) \cdot \mathrm{A} \\
-\left(-1+h\left(x_{1}\right) \cdots h^{\prime}\left(x_{i}\right) \cdots h\left(x_{k}\right) h\left(x_{R}\right) \frac{\pi_{i}}{r}\right) \cdot h^{\prime}\left(x_{i}\right)
\end{array}\right] \\
& -\frac{1}{\mathrm{~A}^{4}}\left[\left\{\begin{array}{r}
\left(-1+h\left(x_{1}\right) \cdots h^{\prime}\left(x_{i}\right) \cdots h\left(x_{k}\right) h\left(x_{R}\right) \frac{\pi_{i}}{r}\right) \cdot h^{\prime}\left(x_{i}\right) \\
+\left(-x_{i}+h\left(x_{1}\right) \cdots h\left(x_{k}\right) h\left(x_{R}\right) \frac{\pi_{i}}{r}\right) \cdot h^{\prime \prime}\left(x_{i}\right)
\end{array}\right\} \cdot \mathrm{A}^{2}\right. \\
& \left.-\left\{\left(-x_{i}+h\left(x_{1}\right) \cdots h\left(x_{k}\right) h\left(x_{R}\right) \frac{\pi_{i}}{r}\right) \cdot h^{\prime}\left(x_{i}\right) \cdot 2 \mathrm{~A} \cdot h^{\prime}\left(x_{1}\right)\right\}\right]
\end{aligned}
$$


From rearranging the latter part and using FOC (4.2), we can simplify above formula, that is,

$$
\begin{aligned}
& =\frac{1}{\mathrm{~A}^{2}}\left[\begin{array}{c}
\left(h\left(x_{1}\right) \cdots h^{\prime \prime}\left(x_{i}\right) \cdots h\left(x_{k}\right) h\left(x_{R}\right) \frac{\pi_{i}}{r}\right) \cdot \mathrm{A} \\
\left.-\left(-1+h\left(x_{1}\right) \cdots h^{\prime}\left(x_{i}\right) \cdots h\left(x_{k}\right) h\left(x_{R}\right) \frac{\pi_{i}}{r}\right) \cdot h^{\prime}\left(x_{i}\right)\right]
\end{array}\right] \\
& -\frac{1}{\mathrm{~A}^{3}}\left[\begin{array}{c}
\left(-x_{i}+h\left(x_{1}\right) \cdots h\left(x_{k}\right) h\left(x_{R}\right) \frac{\pi_{i}}{r}\right) \cdot h^{\prime \prime}\left(x_{i}\right) \cdot \mathrm{A} \\
-\left(-x_{i}+h\left(x_{1}\right) \cdots h\left(x_{k}\right) h\left(x_{R}\right) \frac{\pi_{i}}{r}\right) \cdot h^{\prime}\left(x_{i}\right)^{2}
\end{array}\right]
\end{aligned}
$$

By rearranging, above formula can be finally reduced as follow

$$
=\frac{h^{\prime \prime}\left(x_{i}\right)}{\mathrm{A}^{2}}\left[\begin{array}{l}
\left(h\left(x_{1}\right) \cdots h\left(x_{i-1}\right) h\left(x_{i+1}\right) \cdots h\left(x_{k}\right) h\left(x_{R}\right) \frac{\pi_{i}}{r}\right) \times \\
\left(r+h\left(x_{1}\right)+\cdots h\left(x_{i-1}\right)+h\left(x_{i+1}\right) \cdots+h\left(x_{k}\right)+h\left(x_{R}\right)\right) \cdot+x_{i}
\end{array}\right]
$$

where $\left[\begin{array}{l}\left(h\left(x_{1}\right) \cdots h\left(x_{i-1}\right) h\left(x_{i+1}\right) \cdots h\left(x_{k}\right) h\left(x_{R}\right) \frac{\pi_{i}}{r}\right) \times \\ \left(r+h\left(x_{1}\right)+\cdots h\left(x_{i-1}\right)+h\left(x_{i+1}\right) \cdots+h\left(x_{k}\right)+h\left(x_{R}\right)\right) \cdot+x_{i}\end{array}\right]$ has positive sign and $h^{\prime \prime}\left(x_{i}\right)$ has

negative sign by assumption about hazard rate function. Therefore, $V_{i i}^{i} \equiv \frac{\partial^{2} V^{i}}{\partial x_{i}^{2}}$ has negative sign and this means that SOC for any firm $i(i=1, \cdots, k, R)$ is satisfied. Q.E.D. 
Proof of satisfying $V_{i j}^{i} \equiv \frac{\delta^{2} V^{i}}{\delta x_{i} \delta x_{j}}>0 \quad(i=1, \cdots, k, R ; j=1, \cdots, i-1, i+1, k, R)$

We can check similar process with the proof of satisfying SOC. That is, $V_{i j}^{i}$ is the differentiation of firm $i$ 's FOC with respect to $x_{j}$.

$$
\begin{aligned}
& V_{i j}^{i} \equiv \frac{\partial^{2} V^{i}}{\partial x_{i} \partial x_{j}}=\frac{\partial}{\partial x_{j}}\left(\frac{\partial V^{i}}{\partial x_{i}}\right)=\frac{\partial V_{i}^{i}}{\partial x_{j}}
\end{aligned}
$$

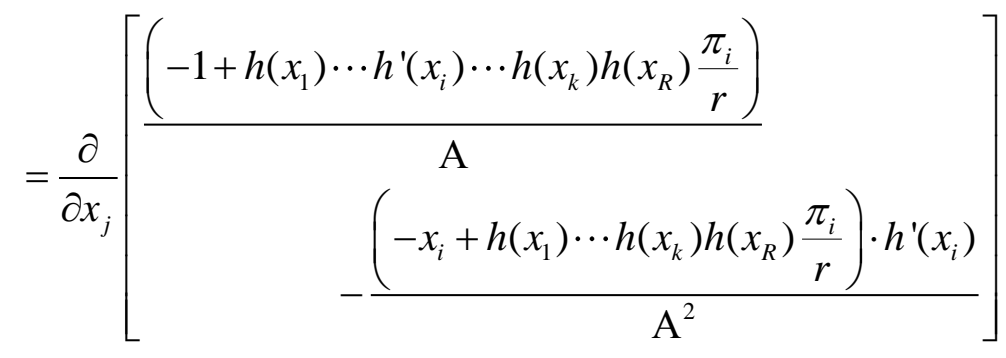

$$
\begin{aligned}
& =\frac{1}{\mathrm{~A}^{2}}\left[\begin{array}{c}
\left(h\left(x_{1}\right) \cdots h^{\prime}\left(x_{i}\right) \cdots h^{\prime}\left(x_{j}\right) \cdots h\left(x_{k}\right) h\left(x_{R}\right) \frac{\pi_{i}}{r}\right) \cdot \mathrm{A} \\
-\left(-1+h\left(x_{1}\right) \cdots h^{\prime}\left(x_{i}\right) \cdots h\left(x_{k}\right) h\left(x_{R}\right) \frac{\pi_{i}}{r}\right) \cdot h^{\prime}\left(x_{j}\right)
\end{array}\right] \\
& -\frac{h^{\prime}\left(x_{i}\right)}{\mathrm{A}^{4}}\left[\begin{array}{r}
\left(h\left(x_{1}\right) \cdots h^{\prime}\left(x_{j}\right) \cdots h\left(x_{k}\right) h\left(x_{R}\right) \frac{\pi_{i}}{r}\right) \cdot \mathrm{A}^{2} \\
-2\left(-x_{i}+h\left(x_{1}\right) \cdots h\left(x_{j}\right) \cdots h\left(x_{k}\right) h\left(x_{R}\right) \frac{\pi_{i}}{r}\right) \cdot \mathrm{A} \cdot h^{\prime}\left(x_{j}\right)
\end{array}\right]
\end{aligned}
$$

From rearranging above formula and using FOC (4.2), we can simplify above formula as follow

$$
\begin{aligned}
& =\frac{1}{\mathrm{~A}^{2}}\left[\begin{array}{c}
\left(h\left(x_{1}\right) \cdots h^{\prime}\left(x_{i}\right) \cdots h^{\prime}\left(x_{j}\right) \cdots h\left(x_{k}\right) h\left(x_{R}\right) \frac{\pi_{i}}{r}\right) \times \\
\left(r+h\left(x_{1}\right)+\cdots+h\left(x_{i-1}\right)+h\left(x_{i+1}\right)+\cdots+h\left(x_{k}\right)+h\left(x_{R}\right)\right)
\end{array}\right] \\
& +\frac{h^{\prime}\left(x_{i}\right)}{[]^{3}} \cdot\left(-x_{i}+h\left(x_{1}\right) \cdots h\left(x_{k}\right) h\left(x_{R}\right) \frac{\pi_{i}}{r}\right) \cdot h^{\prime}\left(x_{j}\right)
\end{aligned}
$$

where we can easily understand that the former formula has positive sign. While the latter formula has positive sign because $h^{\prime}\left(x_{i}\right), h^{\prime}\left(x_{j}\right),\left(-x_{i}+h\left(x_{1}\right) \cdots h\left(x_{k}\right) h\left(x_{R}\right) \frac{\pi_{i}}{r}\right)$, and A have all positive sign. Particularly we can understand $\left(-x_{i}+h\left(x_{1}\right) \cdots h\left(x_{k}\right) h\left(x_{R}\right) \frac{\pi_{i}}{r}\right)$ has positive sign from FOC. Q.E.D. 
Proof of satisfying $V_{i K_{i}}^{i} \equiv \frac{\delta V_{i}^{i}}{\delta K_{i}}>0 \quad(i=1, \cdots, k, R)$

Here $V_{i K_{i}}^{i}$ is the differentiation of firm $i$ 's FOC with respect to $K_{i}\left(\equiv \frac{\pi_{i}}{r}\right)$.

$$
\begin{aligned}
V_{i K_{i}}^{i} \equiv \frac{\partial^{2} V^{i}}{\partial x_{i} \partial K_{i}} & =\frac{\partial}{\partial K_{i}}\left(\frac{\partial V^{i}}{\partial x_{i}}\right)=\frac{\partial V_{i}^{i}}{\partial K_{i}} \\
= & \frac{\partial}{\partial K_{i}}\left[\begin{array}{c}
\frac{\left(-1+h\left(x_{1}\right) \cdots h^{\prime}\left(x_{i}\right) \cdots h\left(x_{k}\right) h\left(x_{R}\right) K_{i}\right)}{\mathrm{A}} \\
\left.-\frac{\left(-x_{i}+h\left(x_{1}\right) \cdots h\left(x_{k}\right) h\left(x_{R}\right) K_{i}\right) \cdot h^{\prime}\left(x_{i}\right)}{\mathrm{A}^{2}}\right]
\end{array}\right. \\
= & \frac{h\left(x_{1}\right) \cdots h^{\prime}\left(x_{i}\right) \cdots h\left(x_{k}\right) h\left(x_{R}\right)}{\mathrm{A}}-\frac{h\left(x_{1}\right) \cdots \cdots h\left(x_{k}\right) h\left(x_{R}\right) \cdot h^{\prime}\left(x_{i}\right)}{\mathrm{A}^{2}}
\end{aligned}
$$

From rearranging above formula, we can simplify as follow

$$
=\frac{1}{\mathrm{~A}^{2}}\left[\begin{array}{c}
\left(h\left(x_{1}\right) \cdots h^{\prime}\left(x_{i}\right) \cdots h\left(x_{k}\right) h\left(x_{R}\right)\right) \times \\
\left(r+h\left(x_{1}\right)+\cdots+h\left(x_{i-1}\right)+h\left(x_{i+1}\right)+\cdots+h\left(x_{k}\right)+h\left(x_{R}\right)\right)
\end{array}\right]
$$

Therefore we can easily understand that the above formula has positive sign. Q.E.D. 
NOTES 